\title{
A discrete population of neurons in the lateral amygdala is specifically activated by contextual fear conditioning
}

\author{
Yvette M. Wilson and Mark Murphy ${ }^{1}$ \\ Department of Anatomy and Cell Biology, University of Melbourne, Melbourne, Victoria 3010, Australia
}

\begin{abstract}
There is no clear identification of the neurons involved in fear conditioning in the amygdala. To search for these neurons, we have used a genetic approach, the fos-tau-lacZ (FTL) mouse, to map functionally activated expression in neurons following contextual fear conditioning. We have identified a discrete population of neurons in the lateral amygdala that are activated specifically following learning. These neurons have the morphology of principal neurons of the amygdala, and are immunoreactive for glutamate. The highly specific localization of these neurons within the lateral amygdala suggests that these neurons may be a discrete population of neurons involved in fear learning.
\end{abstract}

Fear conditioning involves associating a neutral stimulus, such as a context or sound (the conditioned stimulus or CS), with an aversive stimulus, such as a footshock (the unconditioned stimulus or US). After training, the animal displays fearful behavior on being presented with the CS alone. Some of the major areas of the brain that are necessary for expression of fear conditioning have been determined by lesioning experiments, with the amygdala playing a central role in the process (Pitkanen et al. 1997; LeDoux 2000; Maren 2001; Sah et al. 2003; Fanselow and Poulos 2005).

A number of different approaches point to the lateral nucleus of the amygdala (LA) as a crucial site of integration of incoming signals from different parts of the brain (Pape and Stork 2003; Maren and Quirk 2004; Rodrigues et al. 2004; Kim and Jung 2006; LeDoux 2007). Thus, the LA is a prime site into which an association between CS and US might be formed, and which might underlie a significant part of the learning and memory of fear conditioning.

Where these studies point to the LA as being very important in fear conditioning, the identification and localization of the precise changes that are responsible for fear conditioning memory have not been identified. One reason for this is that it has been difficult to identify the neurons that are directly involved in learning and memory. An approach to identifying neurons involved in a particular function is to use markers of neuronal activation, such as the immediate early genes (Tischmeyer and Grimm 1999; Guzowski et al. 2005). Of these genes, c-fos is the most studied and is induced by a wide range of different stimuli (Morgan and Curran 1991; Herrera and Robertson 1996; Chaudhuri 1997; Herdegen and Leah 1998).

Some studies have been undertaken using different immediate early genes or other markers in order to look for patterns of activation in fear conditioning in the LA. In studies of the expression of the NGF1-A and NGF1-B genes, significant increases in labeling were found in the dorsal subnucleus of the LA (LaD) in rats following contextual fear conditioning compared with control rats that received an immediate shock in the context and were not conditioned (Malkani and Rosen 2000a,b). Similar findings were found for another immediate early gene, early growth response gene 1 (Malkani and Rosen 2000a,b). These findings

'Corresponding author.

E-mail m.murphy@unimelb.edu.au; fax 613-9347-5219.

Article is online at http://www.learnmem.org/cgi/doi/10.1101//m.1361509. suggested that there are neurons within the LaD activated specifically by context fear conditioning (Rosen et al. 1998). However, it could not be determined from these studies which neurons were specifically activated by fear conditioning due to the limitations in the resolution of the in situ hybridization technique used to detect expression of the different genes. Related findings have also been demonstrated using $c$-fos and cyclic AMP response elementbinding proteins (Stanciu et al. 2001; Radwanska et al. 2002; Han et al. 2007).

In other studies, auditory fear conditioning was shown to be dependent on activation of ERK/MAP kinase in the LA (Schafe et al. 2000). Using immunohistochemistry for phosphorylated ERK, these studies also showed that auditory fear conditioning resulted in activation of ERK in populations of neurons in dorsal and ventrolateral subnuclei (LaVL) of the LA (Schafe et al. 2000). Following unpaired presentation of tone and shock, 30\% fewer neurons were activated compared with the paired condition, and the overall distribution of activated neurons in the LA appeared similar between both conditions. Thus, it was difficult to determine which of the neurons showing activation were activated in association with fear conditioning and which may have been activated by the different stimuli received by the rats: the shock, the auditory tone, and/or the context. The same group later reported that the LaD contained two neuronal populations with different electrophysiological responses evoked by auditory fear conditioning: a transiently changed population found near the dorsal tip and a longer lasting plastic population more common in ventral regions of the LaD (Repa et al. 2001). They suggested that these different populations of neurons may be differentially involved in learning and long-term memory of fear conditioning.

We have generated transgenic mice in which the tau-lacZ fusion gene is under the regulation of the promoter for the c-fos gene, the fos-tau-lacZ (FTL) mouse (Wilson et al. 2002). In these mice, expression of $\beta$-galactosidase ( $\beta$ gal) in c-fos expressing neurons has been targeted to cell bodies, axons, and dendrites. The advantage over FOS immunohistochemistry or c-fos in situ hybridization results from two principal characteristics of the FTL transgene. First, expression of the transgene is targeted to cell bodies and their processes, and second, transgene activation can be detected either by $\beta$ gal histochemistry or immunohistochemistry. This allows imaging from the macroscopic level of whole regions of the brain to a high-resolution level of a single neuronal process. By comparison, $c$-fos expression is restricted to cell nuclei, 
and thus, imaging using conventional $c$-fos detection techniques does not allow either simple macroscopic imaging or highresolution imaging and analysis of cell bodies and their processes. We have used these mice to identify neurons that might be specifically activated in the learning of context fear conditioning.

The experiments were performed using a computerized fearconditioning system (Med Associates). Conditioning occurred in a Plexiglas training chamber containing a shock-grid floor made of stainless-steel rods. The shock grid was connected to a shockerscrambler unit delivering shocks of defined intensity and duration $(0.15 \mathrm{~mA}$ for $2 \mathrm{sec})$. On the training day, 2-3-mo-old FTL mice ( $n=$ 6) were subjected to the following treatments: The Conditioned group: exposure to context of training chamber for $180 \mathrm{sec}$, then shock, followed by a further $30 \mathrm{sec}$ in training chamber; Immediate Shock group: receive shock within 10 sec of entry into training chamber, followed by $200 \mathrm{sec}$ in training chamber; Context group: exposure to context of training chamber for $210 \mathrm{sec}$ with no shock.

Mice were then removed and returned to their home cages. They were tested for conditioned fear $2 \mathrm{~h}$ after training by placing them in the training chamber for $3 \mathrm{~min}$. Conditioned fear, expressed as freezing or lack of movement, except for breathing, was recorded continuously by an observer blind to the animal's treatment. All experimental procedures were approved by the Institutional Animal Care and Use Committee of the University of Melbourne. The Conditioned group of mice showed a clear freezing response following testing, whereas both Context and Immediate Shock control mice showed only very low levels of freezing (Fig. 1). There was no significant difference in freezing behavior of the Immediate Shock mice compared with the Context control mice.

The FTL mice were then euthanized and their brains sectioned $(100 \mu \mathrm{m})$ and stained for $\beta$ gal as previously described (Wilson et al. 2002; Murphy et al. 2007). The basolateral complex of the amygdala (BLA) has been strongly implicated in the learning of fear conditioning. In particular, it is thought to be a potential site of plasticity for the acquisition of fear conditioning. We thus examined the BLA to look for any learning-specific changes in FTL expression. Within this complex we found clear and highly discrete differences in FTL expression between Conditioned mice and the two nonlearning controls (Fig. 2A-C). More

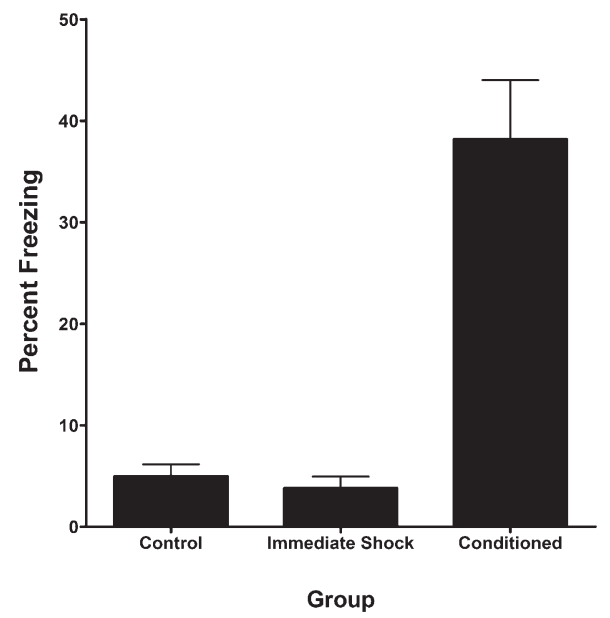

Figure 1. Contextual fear conditioning of $F T L$ mice. FTL mice were placed in a training chamber and either received no shock (Context), were shocked immediately, or shocked after $3 \mathrm{~min}$. The mice were then removed, and $2 \mathrm{~h}$ later were placed back into the training chamber and tested for their fear response by measuring their freezing over a 3-min period. Shown are mean percent freezing \pm SD for each condition. specifically, in mid to posterior regions of the amygdala, conditioning results in FTL expression in a circumscribed cluster of neurons in the ventrolateral nucleus of the LA (LaVL). Based on the mouse atlas of Paxinos and Franklin (2001), this cluster of activated neurons was restricted to the lateral border of the LaVL, with most of the activated neurons being within $150 \mu \mathrm{m}$ of this border (Fig. 2A-C). In the rat, a cytoarchitectural/histochemical study (McDonald 1984) suggests that the ventromedial subdivision of the rodent lateral nucleus extends more laterally then depicted in the Paxinos rodent atlases. If this is the case in mice, the area containing the learning-specific $\mathrm{FTL}^{+}$neurons may span the entire mediolateral extent of the LaVL.

Counts of $\mathrm{FTL}^{+}$neurons within this specific region of the LaVL indicate highly significant differences between Conditioned and the two control groups (Fig. 2D) (one-way ANOVA, $F_{(2,7)}=$ 21.95; $P<0.001)$. In Conditioned mice, there was approximately 3.5 times the number of neurons compared with either of the controls. There were no significant differences in the number of $\mathrm{FTL}^{+}$neurons in the Immediate Shock group compared with the Context control group. The FTL expression in individual neurons was also particularly strong within this cluster in Conditioned animals. Counts were also done of the whole LaVL, as defined by Paxinos and Franklin (2001), which showed a similar trend to that described within the region along the lateral edge of this subnucleus (Fig. 2E). Most of this was accounted for by the neurons within the cluster along the lateral edge. There was an apparent additional small increase in neuron number in both Conditioned and Immediate Shock mice. Given that this additional increase in the number of $\mathrm{FTL}^{+}$neurons was found in both Conditioned and Immediate Shock mice, it was likely that these neurons were activated by shock and not by the association of context and shock.

Counts of $\mathrm{FTL}^{+}$cells did not show any significant differences within other subnuclei in the LA between the different training conditions (Fig. 2E). These findings thus suggest that there is learning-specific activation of a relatively small population of cells within a highly localized region of the LA. We also did not detect any other regions within the BLA that showed learning-specific activation. The basolateral nucleus receives contextual information from the hippocampus, and these projections can induce synaptic plasticity (Maren and Fanselow 1995); however, our experimental design would not detect any context-specific activation, because all mice were exposed to context.

In order to begin characterizing the neurons in the LaVL that showed learning-specific activation, we first obtained high-power images of these cells (Fig. 3A). The $\mathrm{FTL}^{+}$cells in the LaVL from the trained mice appeared as multiprocess stellate cells with a fairly large diameter $(13.4 \pm 3.0 \mu \mathrm{m}, n=18)$. These cells thus had morphological characteristics similar to the main type of neuron found in the LA (McDonald 1982).

To further characterize these neurons, we undertook doublelabeling of brain sections for $\beta$ gal, and for glutamate and GABA, the principal neurotransmitters of excitatory and inhibitory neurons, respectively. Double-labeling immunohistochemistry was undertaken as previously described (Greferath et al. 2004) using antibodies to glutamate and GABA obtained from David Pow (Brisbane, Australia). Unlike other antibodies to neurotransmitters, which often require glutaraldehyde fixation, these antibodies were developed for use in paraformaldehyde fixed tissue, allowing labeling of neurons throughout tissue sections (Pow 1993, 1997; Pow et al. 1995). They have been found to be quite specific for either glutamatergic or GABAergic neurons (Pow 1993, 1997; Pow et al. 1995). We found clear labeling of $>99 \%$ of the $F T L^{+}$neurons with glutamate (Fig. 3B-D; 133 of $134 \mathrm{FTL}^{+}$neurons counted in sections obtained from three different mice), and only very few neurons were found that appeared to show labeling for 
GABA (Fig. 3E-G; four of $166 \mathrm{FTL}^{+}$neurons counted showed any GABA immunoreactivity in sections obtained from three different mice).
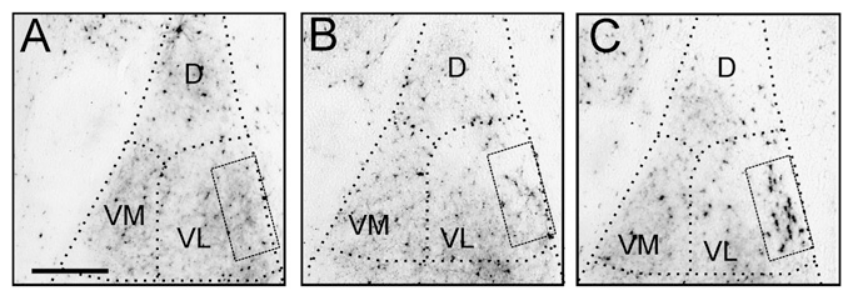

D

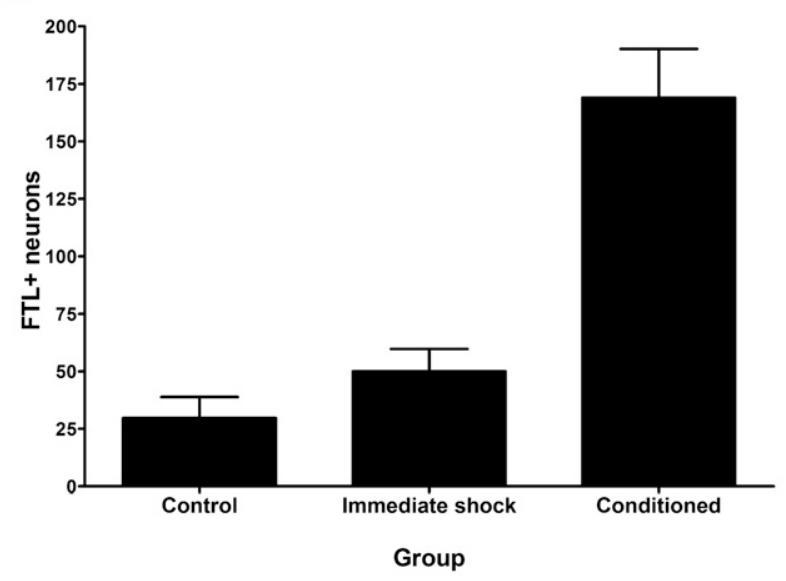

E

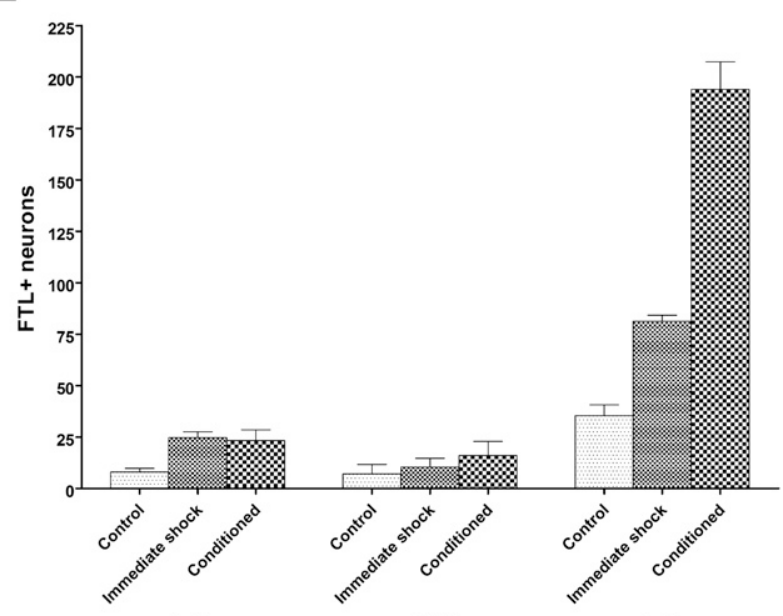

LaD

LaVM

LaVL

Figure 2. Neurons specifically activated by context conditioning in amygdala are localized to an anatomically defined location within LaVL. $(A-C)$ Photomicrogaphs of LA from FTL mice following: $(A)$ Context exposure, $(B)$ Immediate Shock, and $(C)$ Conditioning. $F T L^{+}$neurons were visualized using $\beta$ gal histochemistry. $(D)$ Counts of $F T L^{+}$neurons along the lateral edge of the LaVL in mice following training under different conditions. All sections containing LaVL (Paxinos and Franklin 2001) were photographed and $\mathrm{FTL}^{+}$neurons were counted from these photomicrogaphs by an observer blind to the training condition. Neurons that were counted were contained within $200 \mu \mathrm{m}$ of the border of the LaVL with the external capsule, were clearly positive for the $\mathrm{\beta gal}$ reaction product, and had a stellate morphology with at least two processes. Numbers were pooled from LaVL from both sides of the brain and shown as mean \pm SD. (E) Total counts of $F T L^{+}$neurons in each subnucleus of the LA following training under different conditions. (D) Dorsal; (VL) ventrolateral; (VM) ventromedial. Scale bars for $A-C, 250 \mu \mathrm{m}$.
These results suggest that these neurons are predominantly excitatory. Further immunohistochemical studies, with other markers expressed on pyramidal neurons in BLA, such as Cam kinase II and GluR2/3 (Farb et al. 1995; McDonald et al. 2002), may help to confirm the identity of these neurons. Our findings are also consistent with the proposition that excitatory neurons comprise the major population of immediate early gene-expressing neurons (Knapska et al. 2007), albeit some stimuli can stimulate c-fos expression in inhibitory neurons within the BLA (Reznikov et al. 2008).

There is widespread agreement that the LA plays a principal role in forming CS-US associations in fear conditioning. This view is supported by a plethora of evidence, including necessary neural convergence, conditioning deficits through lesioning and second messenger disruption, and conditioning-induced plasticity in the LA (Maren 2003; Sah et al. 2003; Rodrigues et al. 2004; Kim and Jung 2006; LeDoux 2007). For example, the LA receives CS inputs from multiple systems, including contextual information from the hippocampus. Somatosensory inputs carrying footshock (US) information synapse in the LA and single cells within the LA are activated by both tone or footshock stimulation. These and many other findings all argue that the LA is the site for neural convergence of relevant pathways necessary for associative learning.

Other studies have also implicated subpopulations of neurons within the LA as being activated and involved in the fearconditioning process. In particular, auditory fear conditioning results in activation of ERK in populations of neurons throughout LA and, in particular, in ventral parts of $\mathrm{LaD}$ as well as LaVL (Schafe et al. 2000). More recently, it was reported that LTP at thalamo-LA synapses also induced ERK activation in the same population of neurons in LA (Schafe et al. 2008). Nevertheless, these studies could not determine which of these neurons were activated specifically by fear learning (see above). In our experiments, we could show that $\mathrm{FTL}^{+}$neurons showing learningspecific activation were only present in a confined region along the lateral edge of the LaVL. Given that these studies all show activated neurons along the lateral edge of the LaVL, it points to this confined region as a key site for involvement in fear learning.

The c-fos promoter, which regulates transgene expression in the FTL mice, is partially regulated via ERK activation and subsequent downstream phosphorylation from transcriptional regulators including Elk-1 and CREB (Xia et al. 1996; Adams and Sweatt 2002). Thus, the same populations of neurons that show activation of ERK would also be expected to express c-fos. Partial support for this was provided by the studies of Radwanska et al. (2002), who studied expression of both activated ERK and c-fos following fear conditioning and two-way avoidance training and found similar patterns of expression within LaD. Given that ERK activation is required for fear memory consolidation (Schafe et al. 2000), it follows that the neurons along the lateral edge of the LaVL undergo critical ERK and c-fos-dependent changes that lead to memory consolidation.

The electrophysiology study of Repa et al. (2001) showed that two populations of neurons in the $\mathrm{LaD}$ were activated by fear conditioning, one transiently and the second population showing longer lasting changes in response properties. This second group of neurons was more common in ventral regions of the $\mathrm{LaD}$, and possibly may correlate with neurons showing MAPK activation (Schafe et al. 2000) and FTL expression (this study) following fear conditioning. Repa et al. (2001) also suggest that these cells are principal neurons, based on their firing properties. This is consistent with our findings in which the $F T L^{+}$cells we observe have both the morphology and glutamate immunoreactivity expected of principal neurons. 

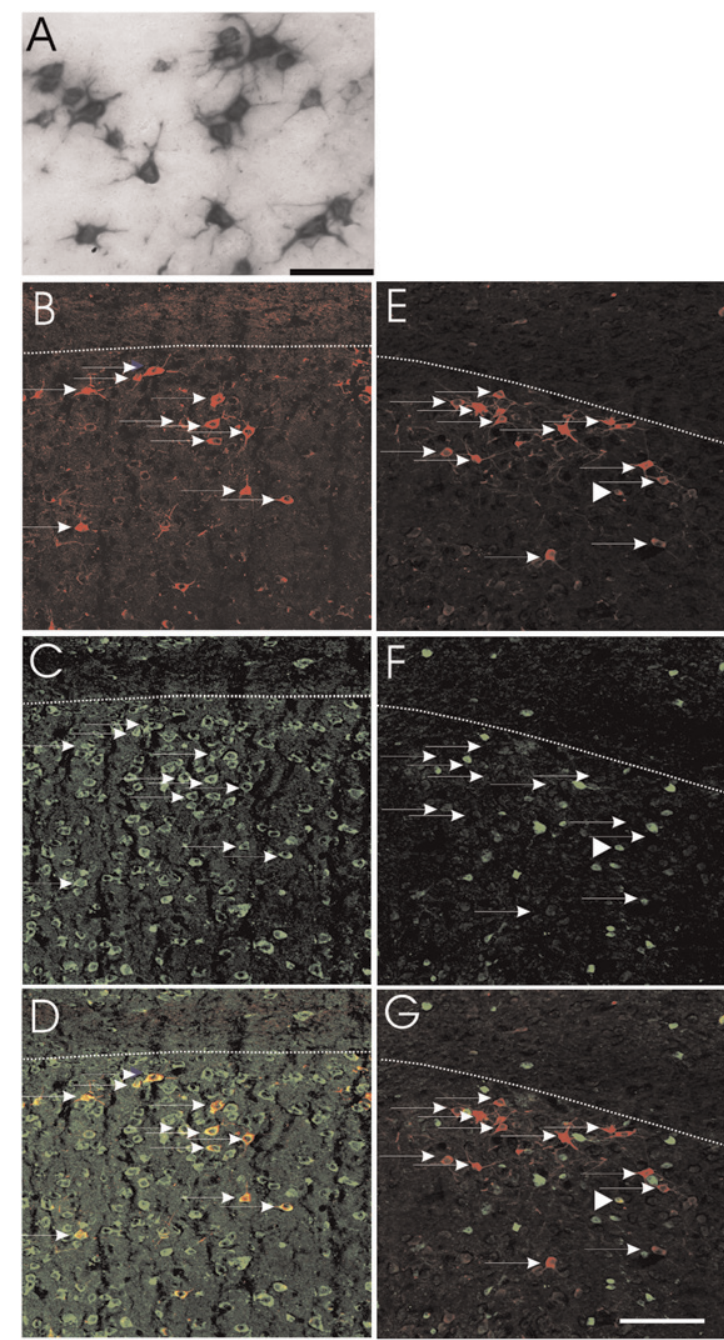

Figure 3. Characterization of Conditioned specific neurons in LaVL. All images are of sections containing the lateral border of LaVL from FTL mice that have been Conditioned. (A) High-power view of $F T L^{+}$neurons in LaVL detected using $\beta$ gal histochemistry. $(B-D)$ The same section immunolabeled for $(B)$ for $\beta$ gal, $(C)$ glutamate, and $(D)$ shows a merge of $\beta$ gal and glutamate labeling. Arrows indicate some of the double-labeled neurons. $(E-G)$ Another section immunolabeled for $(E)$ Bgal, $(F)$ GABA, and $(G)$ shows a merge of $\beta$ gal and GABA labeling. Arrows indicate some $F T L^{+}$ neurons in $E$ and $G$ and the equivalent areas in $F$. Arrowhead indicates a double-labeled neuron. Dotted line indicates lateral border of LA. Scale bars: $(A), 50 \mu \mathrm{m} ;(B-G), 100 \mu \mathrm{m}$.

Other studies have suggested that fear conditioning drives AMPA receptors into a large fraction of postsynaptic neurons in the LA and that encoding of fear memories is widely distributed through the LA (Rumpel et al. 2005). Further research is required to verify this possibility; nevertheless, it is not in disagreement with our findings, because AMPA receptor incorporation into synapses is not dependent on c-fos expression. The population of neurons we have identified may have a role in fear learning quite distinct from that described for the more widespread role for AMPA receptors in the LA. Further, neurons have been identified in BLA, which are activated both by training and retrieval of contextual fear (Reijmers et al. 2007). It would be interesting to undertake similar experiments to determine whether the learningspecific neurons we have identified are also activated following retrieval.
Further research needs to be undertaken to determine how these neurons may be involved in fear learning and memory and what their role is. Could they directly receive convergent inputs from CS and US? Or are they downstream from such cells? Repa et al. (2001) hypothesize that CS-US convergence may occur in one set of neurons in the tip of the $\mathrm{LaD}$, and storage occurs downstream from these cells in ventral regions of this nucleus. Tracing the connections of these neurons may help to determine where they fit in the circuitry for fear conditioning.

\section{Acknowledgments}

We thank Dora Vasiliadis and Lidia Trogrlic for technical assistance and David Pow for antibodies to glutamate and GABA. This work was supported by the National Health and Medical Research Council of Australia.

\section{References}

Adams JP, Sweatt JD. 2002. Molecular psychology: Roles for the ERK MAP kinase cascade in memory. Annu Rev Pharmacol Toxicol 42: 135163.

Chaudhuri A. 1997. Neural activity mapping with inducible transcription factors. Neuroreport 8: iii-vii.

Fanselow MS, Poulos AM. 2005. The neuroscience of mammalian associative learning. Annu Rev Psychol 56: 207-234.

Farb CR, Aoki C, Ledoux JE. 1995. Differential localization of NMDA and AMPA receptor subunits in the lateral and basal nuclei of the amygdala: A light and electron microscopic study. J Comp Neurol 362: 86-108.

Greferath U, Nag N, Zele AJ, Bui BV, Wilson Y, Vingrys AJ, Murphy M. 2004 Fos-tau-LacZ mice expose light-activated pathways in the visual system. Neuroimage 23: 1027-1038.

Guzowski JF, Timlin JA, Roysam B, McNaughton BL, Worley PF, Barnes CA 2005. Mapping behaviorally relevant neural circuits with immediateearly gene expression. Curr Opin Neurobiol 15: 599-606.

Han JH, Kushner SA, Yiu AP, Cole CJ, Matynia A, Brown RA, Neve RL, Guzowski JF, Silva AJ, Josselyn SA. 2007. Neuronal competition and selection during memory formation. Science 316: 457-460.

Herdegen T, Leah JD. 1998. Inducible and constitutive transcription factors in the mammalian nervous system: Control of gene expression by Jun, Fos and Krox, and CREB/ATF proteins. Brain Res Brain Res Rev 28: 370490.

Herrera DG, Robertson HA. 1996. Activation of c-fos in the brain. Prog Neurobiol 50: 83-107.

Kim JJ, Jung MW. 2006. Neural circuits and mechanisms involved in Pavlovian fear conditioning: A critical review. Neurosci Biobehav Rev 30: 188-202.

Knapska E, Radwanska K, Werka T, Kaczmarek L. 2007. Functional internal complexity of amygdala: Focus on gene activity mapping after behavioral training and drugs of abuse. Physiol Rev 87: 1113-1173.

LeDoux J. 2007. The amygdala. Curr Biol 17: R868-R874.

LeDoux JE. 2000. Emotion circuits in the brain. Annu Rev Neurosci 23: 155184.

Malkani S, Rosen JB. 2000a. Induction of NGFI-B mRNA following contextual fear conditioning and its blockade by diazepam. Brain Res Mol Brain Res 80: 153-165.

Malkani S, Rosen JB. 2000b. Specific induction of early growth response gene 1 in the lateral nucleus of the amygdala following contextual fear conditioning in rats. Neuroscience 97: 693-702.

Maren S. 2001. Neurobiology of Pavlovian fear conditioning. Annu Rev Neurosci 24: 897-931.

Maren S. 2003. The amygdala, synaptic plasticity, and fear memory. Ann N Y Acad Sci 985: 106-113.

Maren S, Fanselow MS. 1995. Synaptic plasticity in the basolateral amygdala induced by hippocampal formation stimulation in vivo. J Neurosci 15: 7548-7564.

Maren S, Quirk GJ. 2004. Neuronal signalling of fear memory. Nat Rev Neurosci 5: 844-852.

McDonald AJ. 1982. Neurons of the lateral and basolateral amygdaloid nuclei: A Golgi study in the rat. J Comp Neurol 212: 293-312.

McDonald AJ. 1984. Neuronal organization of the lateral and basolateral amygdaloid nuclei in the rat. J Comp Neurol 222: 589-606.

McDonald AJ, Muller JF, Mascagni F. 2002. GABAergic innervation of $\alpha$ type II calcium/calmodulin-dependent protein kinase immunoreactive pyramidal neurons in the rat basolateral amygdala. J Comp Neurol 446: 199-218. 
Morgan JI, Curran T. 1991. Stimulus-transcription coupling in the nervous system: Involvement of the inducible proto-oncogenes fos and jun. Annu Rev Neurosci 14: 421-451.

Murphy M, Greferath U, Wilson YM. 2007. A method for detecting functional activity related expression in gross brain regions, specific brain nuclei and individual neuronal cell bodies and their projections. Biol Proced Online 9: 1-8.

Pape HC, Stork O. 2003. Genes and mechanisms in the amygdala involved in the formation of fear memory. Ann N Y Acad Sci 985 92-105.

Paxinos G, Franklin KBJ. 2001. The mouse brain in stereotaxic coordinates. Academic Press, San Diego, CA.

Pitkanen A, Savander V, LeDoux JE. 1997. Organization of intra-amygdaloid circuitries in the rat: An emerging framework for understanding functions of the amygdala. Trends Neurosci 20: 517-523.

Pow DV. 1993. Immunocytochemistry of amino-acids in the rodent pituitary using extremely specific, very high titre antisera. $J$ Neuroendocrinol 5: 349-356.

Pow DV. 1997. Immunocytochemical detection of amino acid neurotransmitters in paraformaldehyde-fixed tissues. Methods Mol Biol 72: 103-123.

Pow DV, Wright LL, Vaney DI. 1995. The immunocytochemical detection of amino-acid neurotransmitters in paraformaldehyde-fixed tissues. $J$ Neurosci Methods 56: 115-123.

Radwanska K, Nikolaev E, Knapska E, Kaczmarek L. 2002. Differential response of two subdivisions of lateral amygdala to aversive conditioning as revealed by c-Fos and P-ERK mapping. Neuroreport 13: 2241-2246.

Reijmers LG, Perkins BL, Matsuo N, Mayford M. 2007. Localization of a stable neural correlate of associative memory. Science 317: 1230-1233.

Repa JC, Muller J, Apergis J, Desrochers TM, Zhou Y, LeDoux JE. 2001. Two different lateral amygdala cell populations contribute to the initiation and storage of memory. Nat Neurosci 4: 724-731.

Reznikov LR, Reagan LP, Fadel JR. 2008. Activation of phenotypically distinct neuronal subpopulations in the anterior subdivision of the rat basolateral amygdala following acute and repeated stress. J Comp Neurol 508: $458-472$.

Rodrigues SM, Schafe GE, LeDoux JE. 2004. Molecular mechanisms underlying emotional learning and memory in the lateral amygdala. Neuron 44: 75-91.

Rosen JB, Fanselow MS, Young SL, Sitcoske M, Maren S. 1998. Immediateearly gene expression in the amygdala following footshock stress and contextual fear conditioning. Brain Res 796: 132-142.

Rumpel S, LeDoux J, Zador A, Malinow R. 2005. Postsynaptic receptor trafficking underlying a form of associative learning. Science $\mathbf{3 0 8}$ : 83-88.

Sah P, Faber ES, Lopez De Armentia M, Power J. 2003. The amygdaloid complex: Anatomy and physiology. Physiol Rev 83: 803-834.

Schafe GE, Atkins CM, Swank MW, Bauer EP, Sweatt JD, LeDoux JE. 2000. Activation of ERK/MAP kinase in the amygdala is required for memory consolidation of Pavlovian fear conditioning. J Neurosci 20: 8177-8187.

Schafe GE, Swank MW, Rodrigues SM, Debiec J, Doyere V. 2008. Phosphorylation of ERK/MAP kinase is required for long-term potentiation in anatomically restricted regions of the lateral amygdala in vivo. Learn Mem 15: 55-62.

Stanciu M, Radulovic J, Spiess J. 2001. Phosphorylated cAMP response element binding protein in the mouse brain after fear conditioning: Relationship to Fos production. Brain Res Mol Brain Res 94: 15-24.

Tischmeyer W, Grimm R. 1999. Activation of immediate early genes and memory formation. Cell Mol Life Sci 55: 564-574.

Wilson Y, Nag N, Davern P, Oldfield BJ, McKinley MJ, Greferath U, Murphy M. 2002. Visualization of functionally activated circuitry in the brain. Proc Natl Acad Sci 99: 3252-3257.

Xia Z, Dudek H, Miranti CK, Greenberg ME. 1996. Calcium influx via the NMDA receptor induces immediate early gene transcription by a MAP kinase/ERK-dependent mechanism. J Neurosci 16: 5425-5436.

Received February 5, 2009; accepted in revised form March 25, 2009. 


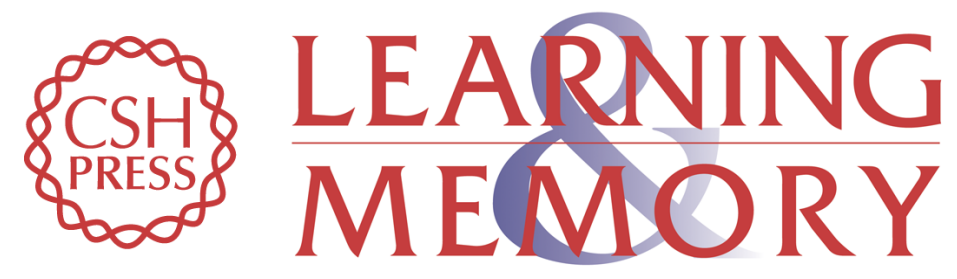

\section{A discrete population of neurons in the lateral amygdala is specifically activated by contextual fear conditioning}

Yvette M. Wilson and Mark Murphy

Learn. Mem. 2009, 16:

Access the most recent version at doi:10.1101//m.1361509

References This article cites 43 articles, 8 of which can be accessed free at: http://learnmem.cshlp.org/content/16/6/357.full.html\#ref-list-1

License

Email Alerting Receive free email alerts when new articles cite this article - sign up in the box at the Service top right corner of the article or click here. 